\title{
Therapeutic strategies in METex14 skipping mutated non-small cell lung cancer
}

\author{
Leylah M. Drusbosky², Richa Dawar ${ }^{3}$, Estelamari Rodriguez ${ }^{3}$ and Chukwuemeka V. Ikpeazu ${ }^{1,3^{*}}$ (1)
}

\begin{abstract}
METex 14 skipping mutations occur in about 3-4\% of lung adenocarcinoma patients and $1-2 \%$ of patients with other lung cancer histology. The MET receptor tyrosine kinase and its ligand hepatocyte growth factor (HGF) are established oncogenic drivers of NSCLC. A mutation that results in loss of exon 14 in the MET gene leads to dysregulation and inappropriate signaling that is associated with increased responsiveness to MET TKIs. Results from GEOMETRY mono-1 and VISION Phase I/II clinical trials demonstrated significant clinical activity in patients treated with the MET Exon 14 skipping mutation inhibitors capmatinib and tepotinib with tolerable toxicity profile. In the GEOMETRY mono-1 trial, capmatinib was especially active in treatment-naive patients supporting the upfront testing of this oncogenic driver. Tepotinib demonstrated superior activity in the pretreated patients in the VISION trial. Savolitinib is another METTKI that has shown efficacy in the first- and second-line settings, including patients with aggressive pulmonary sarcomatoid carcinoma. These studies have demonstrated that these TKIs can cross the blood brain barrier and demonstrated some activity toward CNS metastases. MET Exon 14 skipping mutation is detected by NGS-based testing of liquid or tissue biopsies, with preference for RNA-based NGS. The activity of capmatinib and tepotinib is limited by the development of acquired resistance. Current research is focused on strategies to overcome resistance and improve the effectiveness of these agents. Our aim is to review the current status of MET Exon 14 skipping mutation as it pertains NSCLC.
\end{abstract}

Keywords: NSCLC, MET Exon 14 skipping (METex14), Tyrosine kinase inhibitor, Metastasis

\section{Introduction}

Comprehensive genomic testing is now standard of care in the management of advanced/metastatic non-small cell lung cancer (NSCLC). Genomic testing identifies common or uncommon actionable genomic alterations that impact therapeutic decision making $[1,2]$. The National Comprehensive Cancer Network (NCCN) guidelines recommend testing for certain molecular and immune biomarkers in patients with advanced/metastatic NSCLC to assess eligibility for targeted therapy or immunotherapy [3]. Predictive biomarkers include activating mutations in EGFR, BRAF, KRASG12C, and

\footnotetext{
*Correspondence: cikpeazu@med.miami.edu

${ }^{1}$ University of Miami Sylvester Comprehensive Cancer Center, 8100 SW 10th Street, Ste 3310F, Plantation, FL 33324, USA

Full list of author information is available at the end of the article
}

ERBB2, rearrangements in ALK, ROS1, RET, and NTRK, $M E T$ amplification or exon 14 skipping mutations, PD-L1 expression, and tumor mutational burden. Therapies targeting these biomarkers have demonstrated greater efficacy when compared to chemotherapy [4-6].

The mesenchymal-epithelial transition (MET) is a tyrosine kinase receptor that is mostly expressed in epithelial cells, whose natural ligand is the hepatocyte growth factor (HGF). MET signaling has been demonstrated to involve cell proliferation, migration, invasion, and survival [7]. Genomic alterations in MET include $M E T$ exon 14 skipping mutations (METex14) or activating mutations, $M E T$ gene amplification, and MET protein overexpression. However, the presence of $M E T$ exon 14 skipping mutations is currently, the best-defined predictive biomarker for the use of MET tyrosine kinase original author(s) and the source, provide a link to the Creative Commons licence, and indicate if changes were made. The images or other third party material in this article are included in the article's Creative Commons licence, unless indicated otherwise in a credit line to the material. If material is not included in the article's Creative Commons licence and your intended use is not permitted by statutory regulation or exceeds the permitted use, you will need to obtain permission directly from the copyright holder. To view a copy of this licence, visit http://creativecommons.org/licenses/by/4.0/. The Creative Commons Public Domain Dedication waiver (http://creativeco mmons.org/publicdomain/zero/1.0/) applies to the data made available in this article, unless otherwise stated in a credit line to the data. 
inhibitors (TKIs). MET exon 14 skipping mutations occur in about $3-4 \%$ of patients with adenocarcinomas and in about $1-2 \%$ of patients with other NSCLC histology (squamous and sarcomatoid lung cancer) [8]. It appears that this alteration is more frequent in older women who are non-smokers [9]. MET gene amplification which can be due to the increased gene copy number or due to the transcriptional regulation has been detected in many different types of tumors. It has particularly been associated with a mechanism of resistance to EGFR TKIs with low response to MET inhibitors [10]. While coexistence of $M E T$ ex14 with other oncogenic drivers is not common, METex14 and MET amplification have been reported together [11]. Both METex14 and MET amplifications are associated with poor prognosis in patients with NSCLC.

MET TKIs are divided into types I (subtype Ia and Ib), II, and III. Type Ia inhibitors (e.g., crizotinib) block ATP binding to prevent phosphorylation/activation of the receptor; type Ib inhibitors (e.g., capmatinib, tepotinib, savolitinib, AMG 337) are more specific for MET than type Ia inhibitors. Type II inhibitors (e.g., cabozantinib, glesatinib, merestinib) competitively bind a hydrophobic pocket adjacent to the ATP-binding site. Type III (e.g., tivantinib) inhibitors bind allosteric sites rather than the ATP-binding site [12]. Generally speaking, the outcomes of NSCLC patients with MET exon 14 skipping treated with currently available therapies are poor. The results from the GEOMETRY mono-1 and VISION trials, respectively, led to the recent regulatory approval of capmatinib, and tepotinib was granted priority review for the treatment of this population of NSCLC patient with advanced disease. These results validate MET exon 14 skipping mutations as important oncogenic targets and underscore the need for routine testing by liquid or tissue biopsies.

\section{Molecular biology of METex14 skip mutation}

c-MET is known to be expressed in epithelial cells of various organs including pancreas, liver, kidney, prostate, muscle, and bone marrow. When HGF binds to c-MET, the receptor undergoes homodimerization with subsequent phosphorylation of two tyrosine residues Y1234 and Y1235, located in the catalytic loop of the TK domain. Subsequently, Y1349 and Y1356 located within the carboxy-terminal tail also become phosphorylated, forming a tandem $\mathrm{SH} 2$ recognition motif. This results in recruitment of signaling effectors, including the adaptor proteins growth factor receptor-bound protein 2 (GRB2), src homology 2 domain-containing (SHC), v-crk sarcoma virus CT10 oncogene homolog (CRK) and CRK-like (CRKL); effector molecules phosphatidylinositol 3-kinase (PI3K), phospholipase Cg (PLCg) and SRC, the src homology 2 domain-containing $5^{\prime}$ inositol phosphatase (SHP2); and the signal transducer and activator of transcription STAT3. Unique to c-MET is its assemblage with GRB2-associated binding protein 1 (GAB1) which is a multi-adaptor protein that creates binding sites for additional downstream receptors upon phosphorylation. GAB1 can either bind directly to c-MET or indirectly via GRB2. Downstream responses of c-MET activation include AKT-mediated cell survival, STAT3mediated cell proliferation, and ERK/MAPK-mediated cellular migration and invasion [13] (Fig. 1).

Negative regulation of c-MET is necessary for maintaining a tightly controlled activity. The Y1003 site is a negative regulatory site which is located in the juxtamembrane domain that acts by recruiting $\mathrm{c}-\mathrm{CBL}$. Regulation of c-MET also occurs via its binding to various protein tyrosine phosphatases (PTPs). These PTPs remove phosphoryl groups on the tyrosines within the c-MET kinase or docking sites. Lastly, binding of PLCg to c-MET activates protein kinase C (PKC) which can negatively regulate receptor phosphorylation and activity. Aside from PKC activation, increases in intracellular calcium levels may also result in the negative regulation of c-MET [14].

$M E T$ exon 14 skipping mutations result in base substitutions or indels (likely deletions) that disrupt the branch point of intron 13 , the $3^{\prime}$ splice site of intron 13 , or the $5^{\prime}$ splice site of intron 14 [15]. The region of the protein encoded by exon 14 includes Y1003, which is the binding site of ubiquitin ligase CBL. MET degradation is mediated by ubiquiting ligase CBL. These somatic mutations affect the RNA-dependent splice sites of exon 14 of the gene and activate MET activity via reduction of MET degradation which increases MET stability and activity. There are various molecular variations of $M E T$ exon 14 skipping alterations, as they exhibit highly diverse sequence compositions, making these mutations difficult to detect. The loss of METex14 results in increased MET stability, prolonged signaling upon HGF stimulation, and increased oncogenic potential. MET exon 14 skipping mutations may be may due to genomic deletions ranging in size from a 2-base pair deletion to 193-base pair deletion affecting the splice acceptor or splice donor site, or point mutations involving Y1003 [12].

\section{Detection of METex14 skipping alterations in tissue and liquid biopsies}

$M E T$ exon 14 skipping alterations are a challenge for diagnostic molecular testing. They exhibit high diversity in sequence composition, many variants are novel, and more than half are indel mutations (up to $3 \mathrm{~kb}$ ), which are difficult to detect [15]. These variants can be detected by obtaining a tissue biopsy of the tumor and sequencing 


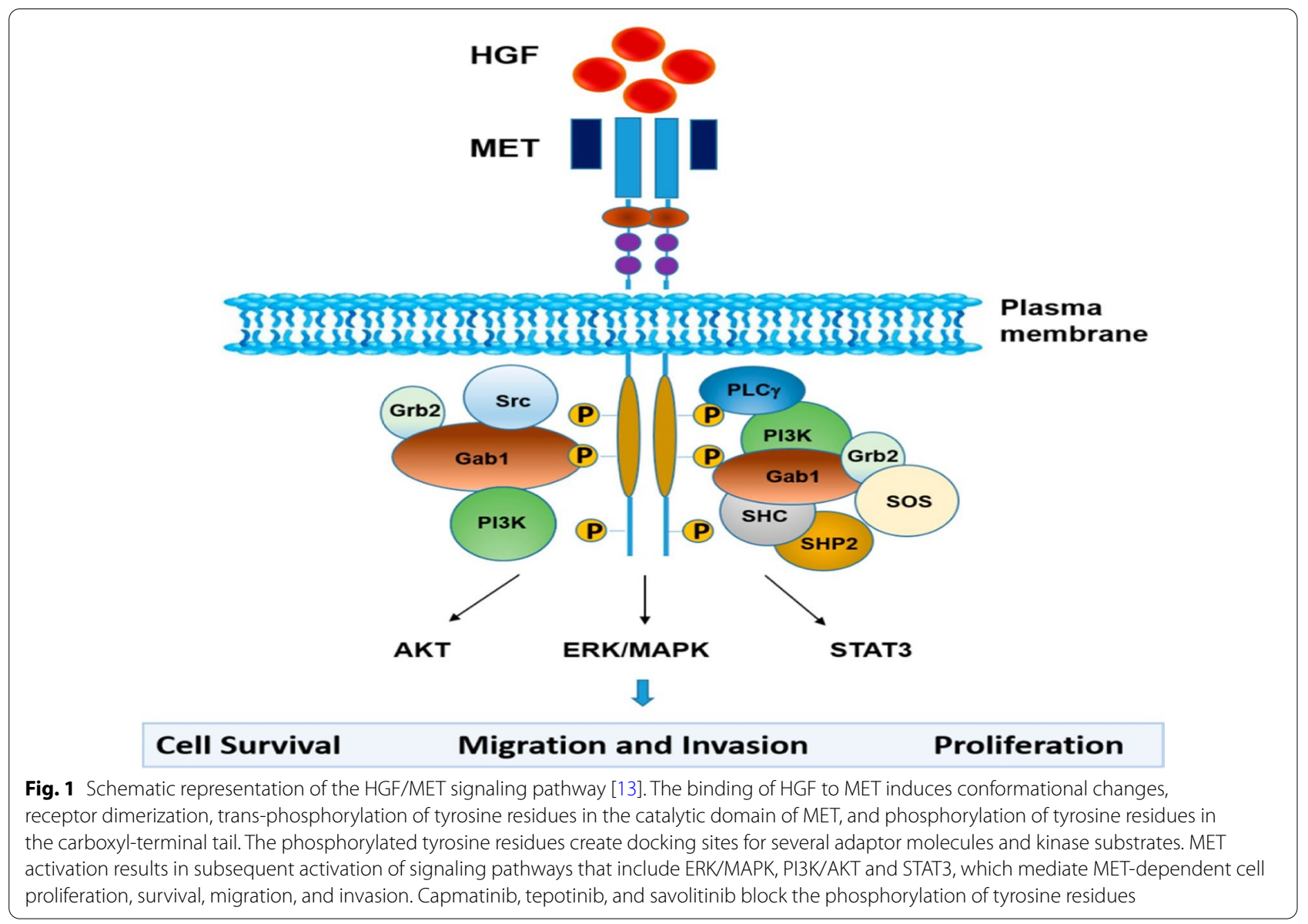

DNA to identify a variant that alters or ablates a splicing site, or RNA sequencing to observe the direct result of altered splicing [16]. Additionally, MET exon 14 skipping mutations can be detected by immunohistochemistry, real-time RT-PCR, and by Sanger sequencing [17, 18]. Utilizing a comprehensive genomic analysis may be the most efficient method to detecting oncogenic driver mutations, including $M E T$, since tissue samples are limited. However, not all patients are able to receive comprehensive genomic profiling, and up to $40 \%$ of tissue biopsies are not adequate for molecular testing $[19,20]$.

Liquid biopsies are a well-validated, FDA-approved molecular diagnostic tool that leverage circulating cellfree DNA (cfDNA) shed from advanced-stage solid tumors, which can be interrogated for tumor-specific alterations utilizing hybrid-capture digital next-generation sequencing [21]. Numerous studies have demonstrated the utility of liquid biopsy in identifying oncogenic driver mutations resulting in favorable clinical outcomes when patients are treated with targeted therapy [22-24]. Additionally, liquid biopsy is utilized to detect acquired molecular mechanisms of resistance to targeted therapy, which can be missed if repeated tissue biopsies are not performed at disease progression $[23,25$, 26].

\section{First-line treatment in patients with advanced disease Capmatinib}

Capmatinib is a small molecule MET inhibitor which has been shown to effectively inhibit the MET pathway both in vitro and in vivo [27]. In a Phase 1 of study of 43 total patients with advanced, pretreated NSCLC, capmatinib at an established RP2D of $400 \mathrm{mg}$ BID, showed preliminary efficacy with manageable toxicity profile in patients with $M E T$ exon 14 mutations and c-MET overexpression [28].

GEOMETRY mono-1 was a Phase 2 study that evaluated capmatinib in 364 patients with stage IIIB/IV NSCLC. Patients were assigned to cohorts based on previous lines of therapy and MET status (MET exon 14 skipping mutation or $M E T$ amplification according to gene copy number in tumor tissue). Capmatinib was dosed at $400 \mathrm{mg}$ BID. The study showed that among patients with a $M E T$ exon 14 skipping mutation, overall response rate was $41 \%$ (95\% CI: 29-53) of 69 patients who had received one or two lines of therapy previously and in $68 \%(95 \%$ 
CI: 48-84) of 28 patients who were treatment naive; the median duration of response was 9.7 months (5.6 to 13.0) and 12.6 months (5.6 to NE), respectively (Table 1 ). The most frequently reported adverse events were peripheral edema (in 51\%) and nausea (in 45\%); these events were mostly of grade 1 or 2 [29] (Table 2). The study also showed that $54 \%$ of patients with brain metastases responded to capmatinib, and 4 patients had a complete

Table 1 Efficacy of capmatinib in GEOMETRY mono-1

\begin{tabular}{ll}
\hline & Previously treated patients ( $n=69)$ \\
ORR (\%) & $41(95 \% \mathrm{Cl}: 29-53)$ \\
Medium DOR (months) & $9.7(95 \% \mathrm{Cl}: 5.6-13.0)$ \\
Medium PFS (months) & $5.4(95 \% \mathrm{Cl}: 5.4-7.0)$ \\
& Treatment-naïve patients ( $n=28)$ \\
ORR (\%) & $68(95 \% \mathrm{Cl}: 48-84)$ \\
Medium DOR (months) & $12.6(95 \% \mathrm{Cl}: 5.6-\mathrm{NE})$ \\
Medium PFS (months) & $12.4(95 \% \mathrm{Cl}: 8.2-\mathrm{NE})$ \\
& Patients with measurable CNS \\
& metastasis $(n=13)$ \\
CR (\%) & 31 \\
PR (\%) & 23
\end{tabular}

NE denotes not evaluable; ORR denotes objective response rate; DOR denotes duration of response; PFS denotes progression-free survival response [30]. Based on these data, capmatinib was approved by the FDA for the treatment of adult patients with metastatic NSCLC whose tumors harbor the MET exon 14 skipping mutation detected by an FDA-approved test.

\section{Tepotinib}

Tepotinib is also an oral, ATP-competitive, and highly selective type 1b MET inhibitor [31]. The efficacy and safety of tepotinib have been assessed in a Phase 1 study in patients with solid tumors, including NSCLC. Tepotinib showed antitumor activity, especially in patients with overexpressed or amplified MET and was tolerated $[31,32]$. The Phase 2 VISION open-label study evaluated tepotinib monotherapy in patients with advanced NSCLC with MET exon 14 skipping mutations who were prospectively assessed by liquid and/or tissue biopsy. A total of 152 patients received tepotinib at $500 \mathrm{mg}$ QD and were followed for at least 9 months. The response rate was $46 \%$ (95\% CI, 36 to 57 ), with a median duration of response of 11.1 months ( $95 \% \mathrm{CI}, 7.2$ to NE) in the combined biopsy group, by independent review. The response rate was $48 \%$ (95\% CI, 36 to 61 ) among 66 patients in the liquid biopsy group and 50\% (95\% CI, 37 to 63) among 60 patients in the tissue biopsy group; 27 patients had

Table 2 Capmatinib safety overview NSCLC with METex14 skipping mutation (GEOMETRY mono-1)

\begin{tabular}{|c|c|c|c|c|}
\hline \multirow[t]{2}{*}{ Adverse events } & \multicolumn{2}{|c|}{ Cohort $4(N=69)$} & \multicolumn{2}{|c|}{ Cohort $5 b(N=28)$} \\
\hline & Total & Grade 3 or 4 & Total & Grade 3 or 4 \\
\hline Any event-no (\%) & 68 (99) & $52(75)$ & $28(100)$ & $21(75)$ \\
\hline Peripheral edema & $37(54)$ & $10(14)$ & $21(75)$ & $3(11)$ \\
\hline Nausea & $31(46)$ & 0 & $13(46)$ & 0 \\
\hline Vomiting & $18(26)$ & 0 & $7(25)$ & 0 \\
\hline Creatinine increased & $23(33)$ & 0 & $10(36)$ & 0 \\
\hline Dyspnea & $19(28)$ & $7(10)$ & $6(21)$ & $2(7)$ \\
\hline fatigue & $18(26)$ & $6(9)$ & $4(14)$ & $1(4)$ \\
\hline Decreased appetite & $15(22)$ & $1(1)$ & $8(29)$ & 0 \\
\hline Constipation & $10(14)$ & $2(3)$ & $4(14)$ & 0 \\
\hline Diarrhea & $12(17)$ & 0 & $5(18)$ & 0 \\
\hline Cough & $10(14)$ & $1(1)$ & $7(25)$ & 0 \\
\hline Back pain & $11(16)$ & $2(3)$ & $4(14)$ & 0 \\
\hline Pyrexia & $9(13)$ & $1(1)$ & $2(7)$ & 0 \\
\hline ALT increased & $8(12)$ & $6(9)$ & $4(14)$ & $2(7)$ \\
\hline Asthenia & $6(9)$ & $3(4)$ & $4(14)$ & $2(7)$ \\
\hline Pneumonia & $7(10)$ & $4(6)$ & $2(7)$ & 0 \\
\hline Weight loss & $9(13)$ & 0 & $3(11)$ & 0 \\
\hline Non-cardiac chest pain & $5(7)$ & $1(1)$ & $1(4)$ & 0 \\
\hline Serious AE & $36(52)$ & $30(43)$ & $14(50)$ & $12(43)$ \\
\hline Event leading to discontinuation & $14(20)$ & $8(12)$ & $6(21)$ & $5(18)$ \\
\hline
\end{tabular}


positive results according to both methods. The investigator-assessed response rate of $56 \%$ (95\% CI, 45 to 66) was similar irrespective of the previous therapy received for advanced or metastatic disease (Table 3). Grade 3 adverse events were seen in $25 \%$ of patients, and the most common grade $3 \mathrm{AE}$ was peripheral edema which was seen in $7 \%$ of patients (Table 4). Molecular response measured in cfDNA, was observed in $67 \%$ of the patients with matched liquid biopsy samples at baseline and during treatment [33]. Based on these data, tepotinib was granted Breakthrough Therapy Designation by the FDA in September 2019 for second-line treatment of patients with metastatic NSCLC harboring MET exon 14 skipping mutations who progressed following platinum-based cancer therapy.

Grade 4 adverse events are not included in the table as there were extremely rare. The listed adverse events occurred in at least $5 \%$ of the patients. However, one patient had a combination of respiratory failure and dyspnea related to interstitial lung disease that was reported as a grade 5 adverse event.

The incidence of adverse events of any grade was similar in 39 patients who had received previous immunotherapy and in 113 patients who did not receive such therapy [33].

\section{Savolitinib}

Savolitinib is a selective oral MET TKI and was tested in a Phase 2 single-arm study across 32 hospitals in China and given conditional approval in China for use in patients with NSCLC with MET exon 14 skipping alterations (METex14) who progressed after previous systemic chemotherapy or unable to receive chemotherapy [34]. Seventy patients with METex14 skipping alterations were enrolled in this study. The median age of study participants was 68.7 years, $92.9 \%$ had stage IV disease, $60 \%$ received prior systemic chemotherapy and
Table 4 Tepotinib safety overview in NSCLC patients with METex14 skipping mutation (VISION Tepotinib trial)

\begin{tabular}{lccl}
\hline Adverse events- $\boldsymbol{N}$ (\%) & All grades & Grade 1 or 2 & Grade 3 \\
\hline Any & $135(89)$ & $93(61)$ & $38(25)$ \\
Peripheral edema & $96(63)$ & $85(56)$ & $11(7)$ \\
Nausea & $39(63)$ & $38(25)$ & $1(1)$ \\
Diarrhea & $33(22)$ & $32(21)$ & $1(1)$ \\
Creatinine increased & $27(18)$ & $26(17)$ & $1(1)$ \\
Hypoalbuminemia & $24(16)$ & $21(14)$ & $3(2)$ \\
Amylase increased & $17(11)$ & $13(9)$ & $3(2)$ \\
Lipase increased & $13(9)$ & $9(6)$ & $4(3)$ \\
Asthenia & $12(8)$ & $11(7)$ & $1(1)$ \\
Decreased appetite & $12(8)$ & $11(7)$ & $1(1)$ \\
Pleural effusion & $12(8)$ & $8(5)$ & $4(3)$ \\
Alopecia & $12(8)$ & $12(8)$ & 0 \\
Fatigue & $11(7)$ & $10(7)$ & $1(1)$ \\
ALT increased & $11(7)$ & $7(5)$ & $3(2)$ \\
AST increased & $10(7)$ & $7(5)$ & $2(1)$ \\
Vomiting & $9(6)$ & $9(6)$ & 0 \\
General edema & $9(6)$ & $5(3)$ & 0 \\
Upper abdominal pain & $8(5)$ & $8(5)$ & 0 \\
\hline
\end{tabular}

35.7\% had more aggressive pulmonary sarcomatoid carcinoma (PSC). At baseline, $24.3 \%$ of patients had brain metastases.

At a median follow-up of 17.6 months, the IRCassessed objective response rate was $49.2 \%$ in the tumor response evaluable set, and $42.9 \%$ in the full analysis. The median PFS was 6.9 months (with a 50\% maturity) and median OS was 14 months. The PFS was reported to be clinically significant in the subgroup of patients with PSC. Treatment-related serious adverse events of grade 3 or more occurred in $32(46 \%)$ patients, the most frequent of which were liver function and peripheral edema. Treatment-related serious adverse events occurred

Table 3 Efficacy of Tepotinib in VISION trial

\begin{tabular}{|c|c|c|c|}
\hline & \multicolumn{3}{|c|}{ Patients with METex14 skipping mutation (efficacy population: $n=99$ ) } \\
\hline & Liquid biopsy $(n=66)$ & Tissue biopsy $(n=60)$ & Combined biopsy $(n=99)$ \\
\hline ORR (\%) & 48 (95\% Cl: 36-61) & 50 (95\% Cl: 37-63) & 46 (95\% Cl: 36-57) \\
\hline Medium DOR (mo) & 9.9 (95\% Cl: 72-NE) & 15.7 (95\% Cl: 9.7-NE) & 11 (95\% Cl: 7.2-NE) \\
\hline \multirow[t]{2}{*}{ Medium PFS (mo) } & 8.5 (95\% Cl: $5.1-11.0)$ & 11.0 (95\% Cl: 5.7-17.1) & 8.5 (95\% Cl: 6.7-11.0) \\
\hline & & & $\begin{array}{l}\text { Patients with brain } \\
\text { metastasis ( } n-11)\end{array}$ \\
\hline ORR (\%) & & & 55 (95\% Cl: 23-83) \\
\hline DOR (mo) & & & 9.5 (95\% Cl: 6.6-NE) \\
\hline PFS (mo) & & & 10.9 (95\% Cl: 8.0-NE) \\
\hline
\end{tabular}

NE denotes no evaluable; ORR denotes objective response rate; DOR denotes duration of response; PFS denotes progression-free survival 
in $27.5 \%$ of patients, the most frequent of which were abnormal liver function (4.3\%), hypersensitivity reaction (2.9\%), and pyrexia (2.9\%). Emergence of FGFR1, EGFR, and $K R A S$ gene amplification at the time of disease progression has been reported as a mechanism of resistance to savolitinib in a case report [35].

\section{Role of immunotherapy in METex14 skipping alterations}

The current NCCN guidelines favor first-line treatment with single-agent targeted therapy for patients with METEx14 mutation instead of chemotherapy or immune checkpoint inhibitors (ICIs) upfront [1]. Despite the high expression of PDL1 in patients with METEx14, the efficacy of ICIs in this group is underwhelming. In a large study of 1,387 lung cancer cases, the expression of PDL1 was reportedly high in $49 \%$ of MET mutated cases (compared to $29 \%$ of MET wild type), while tumor mutation burden was significantly lower in MET mutated cancers compared to wild-type tumors [36]. In a retrospective analysis evaluating immunotherapy activity as monotherapy in advanced NSCLC with oncogenic drivers, the ORR among 36 patients with MET alterations was $16 \%$, with median PFS and OS of 3.4 and 18.4 months, respectively [37]. In another retrospective review, METEx14 mutations were associated with high $(\geq 50 \%)$ PD-L1 expression; but the ORR with immunotherapy was low at $17 \%$ and median PFS 1.9 months [38]. Other studies have shown conflicting results with similar efficacy of ICIs in MET mutated cancers as wild-type tumors. For example, in a review of twenty-five patients with METex14 NSCLC, of whom 13 received an immune checkpoint inhibitor in the second-line setting, six patients had prolonged progression-free survival ( $>18$ months) [39]. Another retrospective multicenter analysis of $30 \mathrm{MET}$ mutated lung cancers confirmed this findings showing an observed response to ICIs of $36 \%$, similar to the nonmutated group [40]. Further prospective data are clearly needed to define the role of ICIs in this distinct subset of oncogene-addicted NSCLC and their potential role in the second-line setting after treatment with a MET TKI upfront.

\section{Mechanisms of resistance to MET TKls}

MET TKIs have shifted the paradigm in the treatment of patients with $M E T$ exon 14 skipping mutation. Unfortunately, the response magnitude and duration of response are limited by primary and acquired resistance to MET TKIs. The molecular mechanisms of this resistance are not clearly elucidated.

There have been several established mechanisms of resistance to MET TKIs such as on-target resistance driven by kinase domain mutations affecting drug binding to the receptor or its ATP affinity, amplification of
$M E T$ exon 14 mutant allele, and off-target resistance mediated by the activation of bypass signaling. There are two kinds of MET TKIs: type I and type II MET TKIs based on its binding interaction [41, 42]. Type I MET TKIs (e.g., crizotinib, capmatinib, tepotinib, and savolitinib) bind to MET in its catalytically active conformation where the aspartic acid-phenylalanine-glycine (DFG) motif projects into the ATP-binding site [43-45]. Type II MET TKIs (e.g., cabozantinib, merestinib, and glesatinib) bind to MET in its inactive DFG-out conformation [42, 46]. Type I MET inhibitors can be subdivided into type Ia (crizotinib) or type Ib (capmatinib, tepotinib, and savolitinib) depending on its interaction with the solvent front G1163 residue [41].

MET mutations in residues D1228 and Y1230 confer resistance to type I MET TKI by weakening the chemical bonds between the drug and its receptor $[41,47,48]$. The solvent front mutation G1163R mediates resistance only to crizotinib but not to type Ib or type II MET inhibitors [49]. In contrast, mutations in residues L1195 and F1200 confer resistance to type II MET inhibitors [42, 49]. It has also been suggested that resistance to type I MET TKI can be overcome by switching to type II MET inhibitors, particularly if resistance is acquired by mutations involving D1228 and Y1230 residues [42, 49]. Off-target mechanisms of resistance result from bypass track activation of downstream oncogenic signaling in MAPK pathway. Wild-type KRAS amplifications, KRAS mutations [41, 47, 50], NF1/RASA1 mutations [51], PI3KCA mutations, $E G F R$ activation have been shown to drive acquired resistance to MET inhibitors [52, 53]. Acquired EGFR amplifications have also been detected in tumor samples from patients whose tumors developed resistance to MET TKIs [41]. Therefore, it is imperative to identify the resistance mechanism to MET TKI by either plasma or tissue next-generation sequencing for the effective targeted treatment of non-small cell lung cancer.

\section{Discussion}

The prognosis with lung cancer remains poor as it remains the leading cause of cancer-related death in the USA. Current therapeutic strategies include traditional chemotherapy, radiation therapy, targeted therapies, and immunotherapies. Actionable mutation within tumors drives the efficacy of targeted therapy. However, tumor heterogeneity remains a challenge for identifying the patient population that may benefit from specific targeted therapy [54].

A meta-analysis of 11 studies with a total of 18,464 patients with NSCLC showed that MET exon 14 skipping mutations were more frequent in women than men, were less likely to be associated with a history of smoking, and were associated with a significantly older age. $M E T$ exon 
14 skipping mutation have also been associated with poor prognosis, but were not associated with an increased risk for stage IV disease $[55,56]$.

The MET exon 14 skipping mutation inhibitors capmatinib, tepotinib, and savolitinib have been proposed for the treatment of adult patients with metastatic NSCLC whose tumors harbor this mutation, irrespective of tumor histology. These TKIs have demonstrated durable response in both untreated and pretreated patients. In treatment-naïve patients, capmatinib demonstrated ORR of $68 \%$, disease control rate of $96.4 \%$, and duration of response of 12.6 months. In previously treated patients, the ORR is $41 \%$, disease control rate is $78.3 \%$, and duration of response is 9.7 months. Thirteen evaluable patients in the cohorts with MET exon 14 skipping had brain metastasis at baseline [57] and intracranial response was $54 \%$. There were $31 \%$ complete responses and $23 \%$ partial responses. Survival data are pending.

In the tepotinib VISION trial, at a median follow-up of 17.4 months, oral tepotinib led to an independently assessed objective response rate (ORR) of $46.5 \%$ among the 99 participants with locally advanced or metastatic disease who had been followed up for a minimum of 9 months at data cutoff. There were no complete responses, as all responses were partial and lasted for a median of 11.1 months. Median progression-free survival was 8.5 months and the overall survival data were not mature. In all, 43 patients were treatment-naïve, while the remaining 56 had received at least one prior line of therapy, but the ORRs by independent review were comparable to that of the overall cohort, at $44.2 \%$ and $48.2 \%$, respectively. This was also the case for most other subgroups, with the largest difference seen for patients with versus without a smoking history, for whom the respective ORRs were $56.5 \%$ and $35.6 \%$ [48].

Despite the durable responses seen with these agents, acquired resistance remains a challenge as in all TKIs. Acquisition or emergence of preexisting clones with mutations in the MET activation loop Y1230 (also known as Y1248) or D1228 (also known as Y1246) has been shown to mediate resistance to type I MET TKI such as crizotinib in NSCLC with MET exon 14 skipping mutation. However, sensitivity to type II kinase inhibitors such as cabozantinib is maintained, thereby providing the rational for sequential therapy $[58,59]$. Increased expression of transforming growth factor $\alpha$ with resultant activation of the EGFR pathway is another cause of resistance [60]. Drug switching and/or combination therapy may be required to target resistance to MET TKIs.

A multitude of new agents and rational combination of agents with $M E T$ exon 14 skipping as target are currently undergoing clinical trials (Table 5). A randomized Phase II trial evaluating the combination of capmatinib with spartalizumab immunotherapy compared to capmatinib alone in treatment-naïve NSCLC harboring $M E T$ exon 14 skipping is currently enrolling in Europe and Japan. Antibody-drug conjugates like telisotuzumab vedotin (ABBV-399), which is a first-in-class conjugate

Table 5 Ongoing MET inhibitor clinical trials [61]

\begin{tabular}{|c|c|c|}
\hline $\begin{array}{l}\text { ClinicalTrials. } \\
\text { gov identifier }\end{array}$ & Study agent & Trial description \\
\hline NCT02609776 & Amivantamab & $\begin{array}{l}\text { A Phase 1, First-in-Human, Open-Label, Dose Escalation Study of JNJ-61186372, a Human Bispecific EGFR and } \\
\text { c-MET Antibody, in Subjects With Advanced Non-Small Cell Lung Cancer }\end{array}$ \\
\hline NCT03175224 & APL-101 & $\begin{array}{l}\text { Phase } 1 / 2 \text { Multicenter Study of the Safety, Pharmacokinetics, and Preliminary Efficacy of APL-101 in Subjects } \\
\text { With Non-Small Cell Lung Cancer With cMETex14 Skip Mutations and cMET Dysregulation Advanced Solid } \\
\text { Tumors }\end{array}$ \\
\hline NCT01639508 & Cabozantinib & $\begin{array}{l}\text { A Phase II Study of Cabozantinib in Patients With RET Fusion-Positive Advanced Non-Small Cell Lung Cancer } \\
\text { and Those With Other Genotypes ROS1 or NTRK Fusions or Increased Met or AXL Activity }\end{array}$ \\
\hline NCT02414139 & Capmatinib & $\begin{array}{l}\text { A Phase II, Multicenter Study of Oral c-MET Inhibitor INC280 in Adult Patients With EGFR Wild-type (wt), } \\
\text { Advanced Non-small Cell Lung Cancer (NSCLC)(Geometry Mono-1) }\end{array}$ \\
\hline NCT04270591 & Glumetinib & $\begin{array}{l}\text { A Phase Ib/II, Open-Label, Multicenter Study to Evaluate the Efficacy and Safety of Glumetinib (SCC244), a } \\
\text { Selective MET Inhibitor in Patients With Advanced Non-Small Cell Lung Cancer Harboring MET alterations }\end{array}$ \\
\hline NCT03539536 & Telisotuzumab vedotin & $\begin{array}{l}\text { Phase 2, Open-Label Safety and Efficacy Study of Telisotuzumab Vedotin (ABBV-399) in Subjects With Previ- } \\
\text { ously Treated c-Met + Non-Small Cell Lung Cancer }\end{array}$ \\
\hline NCT02864992 & Tepotinib & $\begin{array}{l}\text { A Phase II Single-arm Trial to Investigate Tepotinib in Advanced (Locally Advanced or Metastatic) Non-Small } \\
\text { Cell Lung Cancer with METex14 (METex14) Skipping Alterations or MET Amplification (VISION) }\end{array}$ \\
\hline NCT03993873 & TPX-0022 & $\begin{array}{l}\text { Phase } 1 \text { Study of TPX-0022, a MET/CSF1R/SRC Inhibitor, in Patients With Advanced Solid Tumors Harboring } \\
\text { Genetic Alterations in MET }\end{array}$ \\
\hline NCT04077099 & REGN5093 & A Phase 1/2 Study of REGN5093 in Patients with MET-Altered Advanced Non-Small Cell Lung Cancer \\
\hline NCT04323436 & Capmatinib & $\begin{array}{l}\text { A Double-blind, Placebo-Controlled, Randomized, Phase II Study Evaluating the Efficacy and Safety of Cap- } \\
\text { matinib and Spartalizumab vs Capmatinib and Placebo as } 1^{\text {st }} \text { Line Treatment for Advanced NSCLC Patients } \\
\text { With METex14 Skipping Mutation }\end{array}$ \\
\hline
\end{tabular}


of a MET antibody, ABT-700, and the antimicrotibule agent momomethyl auristatin $\mathrm{E}$ have been proposed. Other highly selective MET inhibitors like glumetinib have shown robust antitumor activity in preclinical models and are currently being studied in Phase I/II trials. Boxitinib (APL-101) is also a selective MET inhibitor under investigation in Phase I/II trials as a single agent in patients harboring $M E T$ exon 14 skipping mutation (Table 5). A search of clinicaltrials.gov does not reveal any ongoing trials of $M E T$ Exon 14 skipping mutation inhibitors in the small cell lung cancer space.

The molecular biology and therapeutic implications of MET alterations in NSCLC continue to evolve. Genomic alterations in MET include MET exon 14 skipping mutations or activating mutations, MET gene amplification, and MET protein overexpression, but the presence of $M E T$ exon 14 skipping mutations is presently the bestdefined oncogenic driver and predictive biomarker for the use of MET TKIs. Given the prevalence of MET exon 14 skipping mutations and the poor outcomes in these patients, MET Exon 14 skipping mutations will continue to be an attractive therapeutic target. As far as we know, MET Exon 14 skipping mutation has not been found in small cell lung cancer.

\section{Conclusion}

In conclusion, in the era of precision medicine, it is imperative to evaluate each patient individually. Molecular profiling of the tumor is an essential component of this clinical evaluation process. MET inhibitors are now established TKIs in the treatment of NSCLC patients with exon 14 skipping mutation, which is present in $3-4 \%$ of patients with adenocarcinomas and $1-2 \%$ of patients with other histologies. The challenge remains overcoming resistance to these new agents.

\begin{abstract}
Abbreviations
TKI:Tyrosine kinase inhibitor; ALK: Anaplastic lymphoma kinase; ROS1: ROS proto-oncogene 1; PIK3CA: Phosphatidylinositol-4,5-bisphosphate 3-kinase, catalytic subunit alpha; MET: MET proto-oncogene, receptor tyrosine kinase; BRAF: BRaf proto-oncogene; EGFR: Epidermal growth factor receptor; NTRK: Neurotrophic tyrosine receptor kinase; RET: RET Proto-oncogene; KIF5B: Kinesin family member 5B; CCDC6: Coiled-coil domain-containing protein 6; NCOA4: Nuclear receptor coactivator 4; AKT: AKR mouse thymoma kinase; MAPK: Mitogen-activated protein kinase; JNK: C-Jun N-terminal kinase; MEN 2: Multiple endocrine neoplasia 2; MKI: Multi-kinase inhibitor; NGS: Nextgeneration sequencing; cfDNA: Cell-free DNA; RTK: Receptor tyrosine kinase; RECIST: Response evaluation criteria in solid tumors; ICl: Immune checkpoint inhibitor; ORR: Objective response rate; PFS: Progression-free survival; OS: Overall survival; DCR: Disease control rate; DOR: Duration of response; NCCN: National Comprehensive Cancer Network.
\end{abstract}

\section{Acknowledgements}

We give special thanks to my administrative assistant Clara Wicki for organizing the tables.

\section{Authors' contributions}

Cl carried out conceptualization and formatting, drafted the abstract, introduction, first-line treatment in patients with advanced disease, mechanisms of resistance, and discussion, and prepared Tables 1, 2, 3, and 4. LD drafted the molecular biology of METex14 skipping mutation and diagnostic testing for METex14 skipping mutation. ER prepared Table 5. RD reviewed and edited. All authors read and approved the final mauncsript.

\section{Funding}

This work was not funded.

Availability of data and materials

Not applicable as no datasets were generated or analyzed.

\section{Declarations}

\section{Consent for publication}

Written informed consent for publication was obtained from all participants.

\section{Competing interests}

Dr. Ikpeazu serves on the advisory board of AstraZeneca which also funds some of his clinical trials. He also serves on the advisory board of Cardinal Health Specialty Solutions. Dr. Drusbosky is the Medical Science Liaison for, and owns stocks in Guardant Health. Dr. Rodriguez serves on the advisory board of Boehringer Ingelheim and Oncocyte. She also serves as consultant for Research to Practice and Physician Education Resource. Dr. Dawar serves on the advisory boards of Agendia, Daiichi Sankyo, and AstraZeneca.

\section{Author details}

${ }^{1}$ University of Miami Sylvester Comprehensive Cancer Center, 8100 SW 10th Street, Ste 3310F, Plantation, FL 33324, USA. ${ }^{2}$ Guardant 360, 505 Penobscot Drive, Redwood City, CA 94063, USA. ${ }^{3}$ Division of Medical Oncology, Department of Internal Medicine, University of Miami Miller School of Medicine, 1475 NW 12th Avenue, Miami, FL 33136, USA.

Received: 27 January 2021 Accepted: 10 August 2021

Published online: 23 August 2021

\section{References:}

1. Laufer-Geva S, Rozenblum AB, Peled N, et al. The clinical impact of comprehensive genomic testing of circulating cell-free DNA in advanced lung cancer. JThorac Oncol. 2018;13(11):1705-16.

2. Domchek SM, Mardis E, Carlisle JW, Owonikoko TK. Integrating genetic and genomic testing into oncology practice in ASCO EDUCATIONAL BOOK; 2020. e259-e263.

3. NCCN guidelines, Non-Small Cell Lung Cancer. Version 2.2021. http:// www.nccn.org. Accessed on 29 Dec 2020.

4. Mazieres J, Zalcman G, Crino L, et al. Crizotinib therapy for advanced lung adenocarcinoma and a ROS1 rearrangement: results from the EUROS1 cohort. J Clin Oncol. 2015;33:992-9.

5. Sholl LM, Aisner DL, Varella-Garcia M, et al. Multi-institutional oncogenic driver mutation analysis in lung adenocarcinoma: the Lung Cancer Mutation Consortium experience. J Thorac Oncol. 2015;10:768-77.

6. Planchard D, Besse B, Groen HJM, et al. Dabrafenib plus trametinib in patients with previously treated BRAF(V600E)-mutant metastatic nonsmall cell lung cancer: an open-label, multicentre phase 2 trial. Lancet Oncol. 2016;17:984-93.

7. Smyth EC, Sclafani F, Cunningham D. Emerging molecular targets in oncology: clinical potential of MET/hepatocyte growth-factor inhibitors. Onco Targets Ther. 2014;7:1001-14.

8. Schrock AB, Frampton GM, Suh J, et al. Characterization of 298 lung cancer patients harboring MET exon 14 skipping alterations. J Thorac Oncol. 2016;11:1493-502.

9. Vuong $\mathrm{HG}, \mathrm{Ho}$ ATN, Altibi AMA, et al. Clinicopathological implications of MET exon 14 mutations in non-small cell lung cancer-a systemic review and meta-analysis. Lung Cancer. 2018;123:76-82.

10. Baldacci S, Mazieres J, Tomasini P, Girard N, Guisier F, Audigier-Valette C, Monnet I, Wislez M, Pérol M, Dô P, Dansin E, Leduc C, Giroux Leprieur 
E, Moro-Sibilot D, Tulasne D, Kherrouche Z, Labreuche J, Cortot AB. Outcome of EGFR-mutated NSCLC patients with MET-driven resistance to EGFR tyrosine kinase inhibitors. Oncotarget. 2017;8(62):105103-14.

11. Awad MM, Oxnard GR, Jackman DM, Savukoski DO, Hall D, Shivdasani P, Heng JC, Dahlberg SE, Jänne PA, Verma S, Christensen J, Hammerman PS, Sholl LM. MET Exon 14 mutations in non-small-cell lung cancer are associated with advanced age and stage-dependent MET genomic amplification and c-met overexpression. J Clin Oncol. 2016;34(7):721-30. https:// doi.org/10.1200/JCO.2015.63.4600.

12. Vansteenkiste JF, Van De Kerkhove C, Wauters E, Van Mol P. Capmatinib for the treatment of non-small cell lung cancer. Expert Rev Anticancer Ther. 2019;19:659-71.

13. Owusu BY, Galemmo R, Janetka J, Klampfer L. Hepatocyte growth factor, a key tumor-promoting factor in the tumor microenvironment. Cancers. 2017;9(4):35.

14. Gandino L, Munaron L, Naldini L, et al. Intracellular calcium regulates the tyrosine kinase receptor encoded by the MET oncogene. J Biol Chem. 1991;266(24):16098-104.

15. Frampton GM, Ali SM, Rosenzweig M, et al. Activation of MET via diverse exon 14 splicing alterations occurs in multiple tumor types and confers clinical sensitivity to MET inhibitors. Cancer Discov. 2015;5(8):850-9.

16. Davis KD, Lomboy A, Lawrence CA, et al. DNA-Based versus RNA-based detection of MET Exon 14 skipping events in lung cancer. J of Thorac Oncol. 2019;14(4):737-41.

17. Awad MM, Oxnard GR, Jackman DM, et al. MET Exon 14 mutations in non-small-cell lung cancer are associated with advanced age and stagedependent MET genomic amplification and c-met overexpression. J Clin Oncol. 2016;34(7):721-30.

18. Kim EK, Kim KA, Lee CY, et al. Molecular diagnostic assays and clinicopathologic implications of MET Exon14 skipping mutation in none-small cell lung cancer. Clin Lung Cancer. 2019;20(1):e123-32.

19. Meric-Bernstam F, Brusco L, Shaw K, et al. Feasibility of large-scale genomic testing to facilitate enrollment onto genomically matched clinical trials. J Clin Oncol. 2015;33(25):2753-62.

20. Aggarwal C, Thompson JC, BlackTA, et al. Clinical implications of plasmabased genotyping with the delivery of personalized therapy in metastatic non-small cell lung cancer. AMA Oncol. 2019;5(2):173-80.

21. Odegaard JI, Vincent JJ, Mortimer S, et al. Validation of a plasma-based comprehensive cancer genotyping assay utilizing orthogonal tissue- and plasma-based methodologies. Clin Cancer Res. 2018;24(15):3539-49.

22. Reckamp KL, Patil T, Kirtane K, et al. Duration of targeted therapy in patients with advanced none-small cell lung cancer identified by circulating tumor DNA analysis. Clin Lung Cancer. 2020;21(6):545-52.

23. Mack PC, Banks KC, Espenschied CR, et al. Spectrum of driver mutations and clinical impact of circulating tumor DNA analysis in non-small cell lung cancer: analysis of over 8000 cases. Cancer. 2020;126:3219-28.

24. Helman E, Nguyen M, Karlovich CA, et al. Cell-free DNA next-generation sequencing prediction of response and resistance to third-generation EGFR inhibitor. Clin Lung Cancer. 2018;19(6):518-30.

25. McCoach CE, Blakely CM, Banks KC, et al. Clinical utility of cell-free DNA for the detection of ALK fusions and genomic mechanisms of ALK inhibitor resistance in non-small cell lung cancer. Clin Cancer Res. 2018;24(12):2758-70.

26. Thompson JC, Yee SS, Troxel AB, et al. Detection of therapeutically targetable driver and resistance mutations in lung cancer patients by nextgeneration sequencing of cell-free circulating tumor DNA. Clin Cancer Res. 2016;22(23):5772-82.

27. Reungwetwattana $T$, Liang $Y$, Zhu V, et al. The race to target MET exon 14 skipping alterations in non-small cell lung cancer: the why, the how, the who, the unknown, and the inevitable. Lung Cancer. 2017;103:27-37.

28. Schuler MH, Berardi R, Lim W-T, et al. Phase (Ph) I study of the safety and efficacy of the CMET inhibitor capmatinib (INC280) in patients (pts) with advanced cMET+ non-small cell lung cancer (NSCLC). J Clin Oncol. 2016;34(15 Suppl):9067-9067.

29. Wolf J, Seto T, Han J-Y, et al. Capmatinib in MET Exon 14-mutated or METamplified non-small-cell lung cancer. N Engl J Med. 2020;383:944-57.

30. Garon EB, Heist RS, Seto T, et al. CT082 - Capmatinib in METex14-mutated (mut) advanced non-small cell lung cancer (NSCLC): Results from the phase II GEOMETRY mono-1 study, including efficacy in patients (pts) with brain metastases (BM) [abstract]. Cancer Res. 2020;60 (16 Suppl): Abstract CT082.
31. Bladt F, Faden B, Friese-Hamim M, et al. EMD 1214063 and EMD 1204831 constitute a new class of potent and highly selective c-Met inhibitors. Clin Cancer Res. 2013;19(11):2941-51.

32. Falchook GS, Kurzrock R, Amin HM, et al. Efficacy, safety, biomarkers, and Phase II dose modeling in a Phase I trial of the oral selective c-Met inhibitor tepotinib (MSC2156119). J Clin Oncol. 2015;33(15 Suppl):2591-2591.

33. Paik PK, Felip E, Veillon $R$, et al. Tepotinib in non-small-cell lung cancer with MET Exon 14 skipping mutations. N Engl J Med. 2020;383:931-43.

34. Lu S, Fang J, Li X, Cao L, Zhou J, Guo Q, Liang Z, Cheng Y, Jiang L, Yang N, Han Z, Shi J, Chen Y, Xu H, Zhang H, Chen G, Ma R, Sun S, Fan Y, Li J, Luo X, Wang L, Ren Y, Su W. Once-daily savolitinib in Chinese patients with pulmonary sarcomatoid carcinomas and other non-small-cell lung cancers harbouring MET exon 14 skipping alterations: a multicentre, single-arm, open-label, phase 2 study. Lancet Respir Med. 2021; 21:S22132600(21)00084-9. https://doi.org/10.1016/S2213-2600(21)00084-9. Epub ahead of print.

35. Han S, Fang J, Lu S, Wang L, Li J, Cheng M, Ren Y, Su W. Response and acquired resistance to savolitinib in a patient with pulmonary sarcomatoid carcinoma harboring MET exon 14 skipping mutation: a case report. Onco Targets Ther. 2019;12:7323-8.

36. Awad MM, Lee JK, Madison R, et al. Characterization of 1,387 NSCLCs with MET exon 14 (METex 14) skipping alterations (SA) and potential acquired resistance (AR) mechanisms. J Clin Oncol. 2020;38(15 Suppl):9511-9511.

37. Mazieres J, Drilon A, Lusque A, et al. Immune checkpoint inhibitors for patients with advanced lung cancer and oncogenic driver alterations: results from the IMMUNOTARGET registry. Ann Oncol; Published online 24 May 2019;mdz167. https://doi.org/10.1093/annonc/mdz167.

38. Sabari JK, Leonardi GC, Shu CA, et al. PD-L1 expression, tumor mutational burden, and response to immunotherapy in patients with MET exon 14 altered lung cancers. Ann Oncol. 2018;29:2085-91.

39. Mayenga M, Assié JB, Monnet I, et al. Durable responses to immunotherapy of non-small cell lung cancers harboring MET exon-14-skipping mutation: a series of 6 cases. Lung Cancer. 2020;150:21-5.

40. Guisier F, Dubos-Arvis C, Viñas F, Doubre H, Ricordel C, Ropert S, Janicot H, Bernardi M, Fournel P, Lamy R, Pérol M, Dauba J, Gonzales G, Falchero L, Decroisette C, Assouline P, Chouaid C, Bylicki O. Efficacy and safety of Anti-PD-1 immunotherapy in patients with advanced NSCLC With BRAF, HER2, or MET mutations or RET translocation: GFPC 01-2018. J Thorac Oncol. 2020;15(4):628-36.

41. Recondo G, Bahall M, Awad MM, et al. Molecular mechanisms of acquired resistance to MET tyrosine kinase inhibitors in patients with MET Exon 14-mutant NSCLC. Clin Cancer Res. 2020;26(11):2615-25.

42. Engstrom LD, Aranda R, Lee M, Christensen JG, et al. Glesatinib exhibits antitumor activity in lung cancer models and patients harboring MET Exon 14 mutations and overcomes mutation-mediated resistance to type I MET inhibitors in nonclinical models. Clin Cancer Res. 2017;23(21):6661-72.

43. Drilon A, Clark JW, Weiss J, Ignatius Ou S-H, et al. Antitumor activity of crizotinib in lung cancers harboring a MET exon 14 alteration. Nat Med. 2020;26(1):47-51.

44. Paik P, Drilon A, Ladanyi M, et al. Response to MET inhibitors in patients with stage IV lung adenocarcinomas harboring MET mutations causing exon 14 skipping. Cancer Discov. 2015;5(8):842-9.

45. Wolf J, Seto T, Han J-Y, et al., Results of the GEOMETRY mono-1 phase II study for evaluation of the MET inhibitor capmatinib (INC280) in patients (pts) with METAex14 mutated advanced non-small cell lung cancer (NSCLC). Ann Oncol. 2018;29:viii741-viii742.

46. Vijayan RSK, Peterson JR, Dunbrack RL Jr, Levy RM, et al. Conformational analysis of the DFG-out kinase motif and biochemical profiling of structurally validated type II inhibitors. J Med Chem. 2015;58(1):466-79.

47. Bahcall M, Awad MM, Janne PA, et al. Amplification of wild-type KRAS imparts resistance to crizotinib in MET Exon 14 mutant non-small cell lung cancer. Clin Cancer Res. 2018;24(23):5963-76.

48. Heist RS, Sequist LV, Borger D, et al. Acquired resistance to crizotinib in NSCLC with MET Exon 14 skipping. J Thorac Oncol. 2016;11 (8):1242-5.

49. Fujino T, Kobayashi Y, Suda K, Mitsudomi T, et al. Sensitivity and resistance of MET Exon 14 mutations in lung cancer to eight MET tyrosine kinase inhibitors in vitro. J Thorac Oncol. 2019;14(10):1753-65.

50. Suzawa K, Offin M, Somwar R, et al. Activation of KRAS mediates resistance to targeted therapy in MET Exon 14-mutant non-small cell lung cancer. Clin Cancer Res. 2019;25(4):1248-60. 
51. Guo R, Offin M, Drion A, et al. MET Exon 14-altered lung cancers and MET inhibitor resistance. Clin Cancer Res. 2021;27(3):799-806.

52. McDermott U, Pusapati RV, Settleman J, et al. Acquired resistance of non-small cell lung cancer cells to MET kinase inhibition is mediated by a switch to epidermal growth factor receptor dependency. Cancer Res. 2010;70(4):1625-34.

53. Nisa $L$, Hafliger $P$, Poliakova $M$, et al. PIK3CA hotspot mutations differentially impact responses to MET targeting in MET-driven and non-driven preclinical cancer models. Mol Cancer. 2017. https://doi.org/10.1186/ s12943-017-0660-5.

54. De Mello RA, Neves NM, Antoniou G, et al. The role of MET inhibitor therapies in the treatment of advanced non-small cell lung cancer. J Clin Med. 2020;9(6):1918. https://doi.org/10.3390/jcm9061918.

55. Vuong HG, Ho ATN, Altibi AMA, et al. Clinicopathological implications of MET exon 14 mutations in non-small cell lung cancer-a systematic review and meta-analysis. Lung Cancer. 2018;123:76-82.

56. Vansteenkiste JF, Van De Kerkhove C, Wauters E, Van Mol P. Capmatinib for the treatment of non-small cell lung cancer. Expert Rev Anticancer Ther. 2019;19(8):659-71.
57. Wolf J, Seto T, Han J, et al. Capmatinib in METex14-mutated advanced non-small cell lung cancer (NSCLC): efficacy data from the phase II GEOMETRY mono-1 study. J Clin Oncol. 2019;37(15 Suppl):9004-9004.

58. Ou SI, et al. Emergence of preexisting METY1230C mutation as a resistance mechanism to crizotinib in NSCLC with MET Exon 14 skipping. J Thorac Oncol. 2017;12(1):137-40.

59. Li A, et al. Acquired MET Y1248H and D1246N mutations mediate resistance to MET inhibitors in non-small cell lung cancer. Clin Cancer Res. 2017;23(16):4929-37.

60. Tiedt $R$, Degenkolbe $E$, Furet $P$, et al. A Drug resistance screen using a selective MET inhibitor reveals a spectrum of mutations that partially overlap with activating mutations found in cancer patients. Cancer Res. 2011;71(15):5255-64

61. www.clinicaltrials.gov. (2021). Accessed on 16 Jan 2021.

\section{Publisher's Note}

Springer Nature remains neutral with regard to jurisdictional claims in published maps and institutional affiliations.
Ready to submit your research? Choose BMC and benefit from:

- fast, convenient online submission

- thorough peer review by experienced researchers in your field

- rapid publication on acceptance

- support for research data, including large and complex data types

- gold Open Access which fosters wider collaboration and increased citations

- maximum visibility for your research: over $100 \mathrm{M}$ website views per year

At BMC, research is always in progress.

Learn more biomedcentral.com/submissions 